\title{
Brain Study Analyzer using Handwriting (BASH)
}

\author{
Ambreen Jabbar \\ Student Faculty of Computer Sciences \\ Preston University,Islamabad Campus \\ Islamabad, Pakistan
}

\author{
Malik Sikandar Hayat Khiyal, PhD \\ Professor Faculty of Computer Sciences \\ Preston University,Islamabad Campus \\ Islamabad, Pakistan
}

\begin{abstract}
Thisstudy describes the person thinking that how brain communicates through handwriting styles, thinking behavior using brainwaves and brain activity models. Everything put on paper is a response of two way circuit between brain and motor reflex muscles of hand. Brain can work on different layers and multiple voxel. Different layers communication are interconnected with each other, Coding of brain with different brain parts activates using our emotions stress moods and ability to séance. In this paper BASH Analyzer technique take different samples and describe how brain communicate through handwriting and define the personality predictions according to brain functions. It evaluates behavior of different writing samplesby differentiating good or bad writer characteristic by evaluating five intelligence factors: chosen appropriate words, common words, Preposition analyzer, Case sensitive, Vowels analyzer are considered. These features are calculated by classification of Support Vector Machine through Artificial Neural Network and BrainIntelligence Technique.
\end{abstract}

\section{General Terms}

Brain Intelligence and Machine Learning.

\section{Keywords}

Voxel, Perspective, Pet-rioted, Trunk, Sensor.

\section{INTRODUCTION}

This study enhances methodologies with new features. There are many researchers who work about handwriting analyses but emphasize on characteristic that how writing isdifferent from other focusing on words and spacing between the words. Based on the characteristic they differentiate writing samples. But we elaborate this study with brain wave Communication. This study focus on how a person think and how a person communicate through their writing, how a person improve their way of thinking behavior to impress others, and how to influence others. Every person has different way of thoughts and their brain work accordingly. This study is best to attract other, status toward moods, stress, happy and to judge yourself-using Brain Study Analyzer with the help of writing samples [1].

In this study a theme or topic used to multiple writers to write a sentence in it. Every writer write their different point of views through their mind then chose the selected words with their own perceptions of how a person perceived.

This study can help in advance level methodology like in social media, exams, and interviews. If you want to test and Challenge a person with their brain analyzer technique using sentence feature which of the sample is best keen Observer, Intellectual, Talkative, Open-minded, Soft hearted, dual minded, Pet rioted and creative. This Research is very helpful to judge a person with brain analyzer which defines behavior of human mindwith their writing samples and a methodology of sentence Analyzer. This study define individual characteristic and compare different samples with others whose handwriting sample is more optimized, motivated, potential power, Devoted, Social person, keen observer, hard worker and ability to achieve a goal. Some person can have a lot of ambitions but they do not struggle to achieve goals due to their laziness, some can planned a lot but not emphasize on how to polish her/himself. Our brain study analyzer also provides tips to open the mind and prepare the mind to accept different challenges.

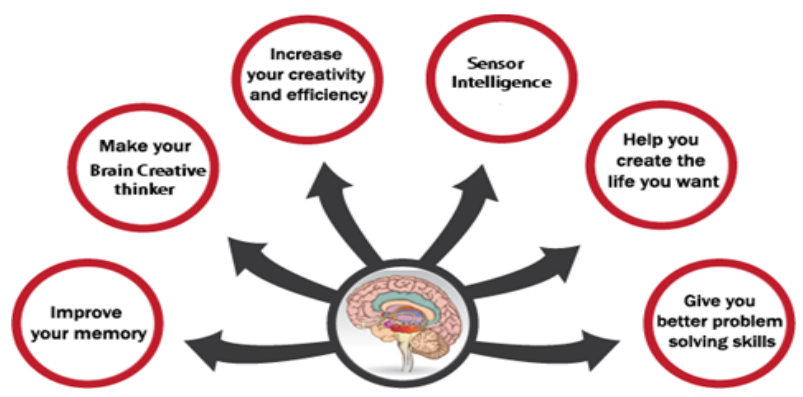

Figure 1Brain Function [1]

Every person has own handwriting style represent his/her personality, and there's good reason to look for which followed their personality in their handwriting .This Study want to followed their personality by many reasons may be to do just for fun or job investigation or want to better understand partner, competitor, family member, friends and even yourself. This Study extracts the different aspects of our life for example ambition, originality, power, doubts, shyness, possible flaws (faults). When we are giving any excite pattern of handwriting it should have following characteristics:

i. Specific shape of letters define moods

ii. Having equal times or space between them to define personality.

\section{TYPES OF HANDWRITING}

\section{ANALYSIS}

During analysis this study can categories into different types

i. This Study extracted personality traits in another case to extract compatibility person. These two main categories and contains many subcategories.

ii. This Study take example of cursive case where uncertain letter and words after they are poorly liked and even missing.

iii. On the other side the hand print words are more reliable and much easier to identify. Result Calculate with categorized options which define 
whose hand writing samples is best with their personality observer using brain study.

\section{METHODOLOGIES}

Method depends on the nature of writing or information to be extracted from it. Brain is like electrical waves so when we think or observe, Every wave can activate. Brain activity differs when person type letters. When person saw latters they had earlier printed in their mind but not typed, this act is an activity in the left inferior frontal gyrus in the left anterior cingulate cortex, it involve in decision making and attention. Brain gives impulse to your hand, this imprinted on paper through the pen that's impulse released by the pen is interpreted on mind and then our BASH analyzer, who capture brain waves through handwriting which define personality. Person enhances their intelligence through BASH Analyzer. [2]

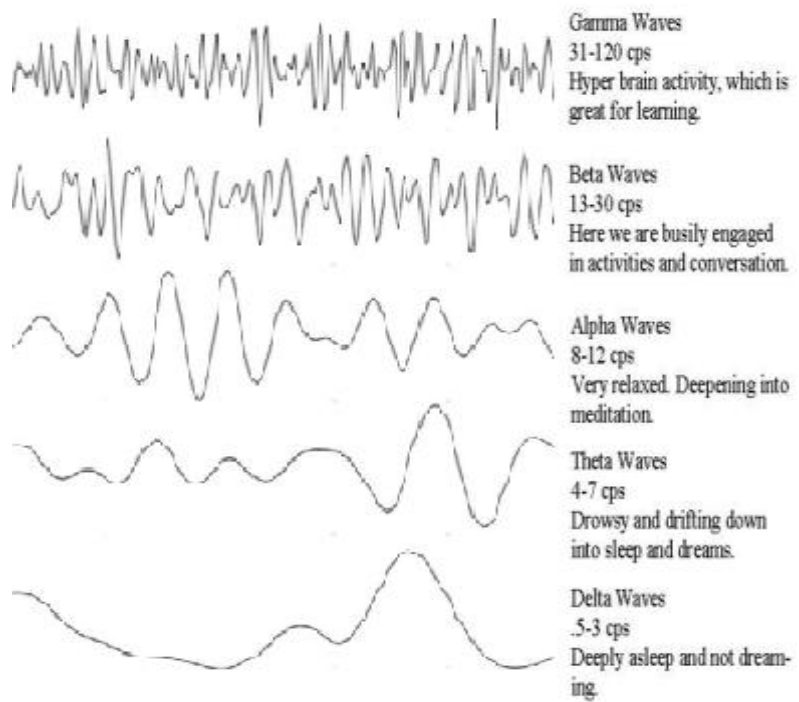

Figure 2 Brain Wave Graph[2]

Figure2 shows the brain waves communication working rest, motivation all are forms of brain that communicate. Gama Waves 31-120(cycle per second) Hyper brain activity, Beta Waves 13-30cps busily engaged in activities and conversation, Alpha Waves $8-12$ cps very relaxed depending into meditation, Theta waves $4-7 \mathrm{cps}$ sleep and dreams, Delta waves 5-3cps Deeply asleep not dreaming[3]. Brain is main part that control full body and emotions, and feeling that this studyanalyze our self by feelings emotions using brain study analyzer. Brain can also associate with stress Hormones and Emotional functions of our mind. Science has proven that brain control every function of our body how we write, read body movement for example when this study want to write something on papercan hold a pen or pencil and placing on paper and the movement it may across the page these all controlling by nerves that move from brain[3].

Table 1.BASH Analyzer

\begin{tabular}{|c|c|c|c|c|}
\hline $\begin{array}{c}\text { Chosen } \\
\text { words }\end{array}$ & $\begin{array}{c}\text { Common } \\
\text { Words }\end{array}$ & $\begin{array}{c}\text { Preposition } \\
\text { Analyze }\end{array}$ & $\begin{array}{c}\text { Case } \\
\text { Sensitive }\end{array}$ & $\begin{array}{c}\text { Vowel } \\
\text { Analyze }\end{array}$ \\
\hline \multicolumn{3}{c|}{ Processing Test } \\
\hline \multicolumn{3}{c|}{ Pomparing sample(Good writer, Bad writer) } \\
\hline
\end{tabular}

i. Beta brain waves are organized by logical, analytical and intellectual thinking, verbal communication, and correct knowledge of ones surroundings this wave can helpful in Bash Analyzer for finding verbal ability in writing.

ii. Alpha waves most commonly activate when we are calm and relaxed, yet mentally alert, energy healing, daydreaming and happy.

iii. Thetawaves are characterized by being deeply relaxed inwardlyfocused. This state placed between being asleep and being awake where all things are possible, motivation to alert goals and new behavior patterns

iv. Deltawaves are associates with being extremely relaxed, characterized by deep dreamless sleep basically it is low task activity

v. Gamma waves active when we are learning processing new information. When we are setting intentions and manifesting and visualization

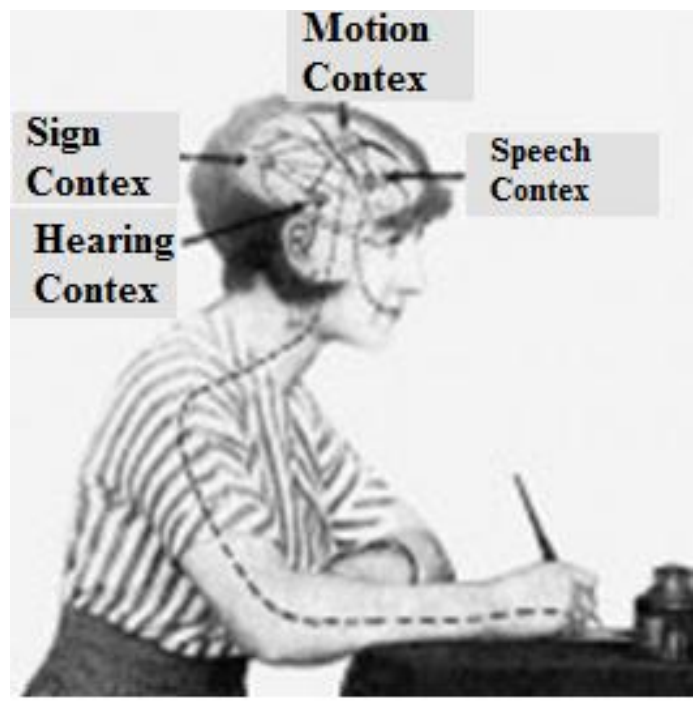

Figure 3Brain Writing [3]

Figure2 shows the structure how our blood circulate in our body and brain functions communicate through handwriting three main function motor cortex, sign cortex speech cortex involve during writing.[4][5]

\subsection{Structure of Blood Circulation}

Structure of blood circulation is as fallows.

i. Collecting Samples

ii. Filtered words

iii. Comparing (verb, Vowels, Prepositions, synonymous)

iv. Perspective Focus

v. Psychological Factors (Man \& Women sample comparison)

vi. Defining Moods

Table1 BASH Analyzer review past papers and define personality forum based on the Table 3Personality Forum. 
i. Chosen Words: Focus on the words that writer used

ii. Common Words: Define common thinker strategy

iii. Preposition Analyze: Define preposition using filtered words that already provided sentence theme to the analyzer.

iv. Case Sensitive: Define spacing, Towering, Insufficient, Enormous, large and small words

v. Vowel Analyzer: Read the dictionary

vi. Processing Test: This can process the full structure of samples

vii. Comparing Samples: Define difference of good or bad writer as brain waves focused through hand.

viii. Personality Focus: Define personality traits on the basis of good and bad writer characteristic.

ix. Result: Define personality basis of Table3

\section{RESULTS}

Processing Test in table1 can read Sentence and facilitate people through test technique in which sentence themes is given for writers to read these sentence fast.

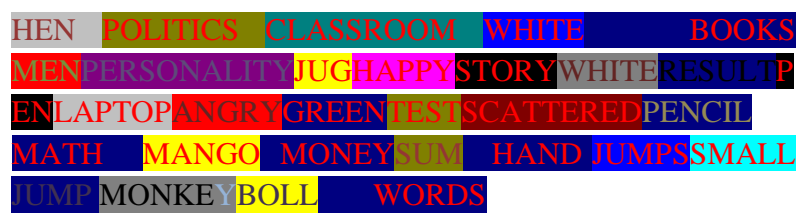

Figure 4Psychological Factors[5]

If you are reading words you are using right brain mode but if you are focusing on colors you are using your left brain mode this is a physiological factor that define individual thoughts of reading and writing according to whole brain model is shown in figure 4.This technique tell you about your personality thinking you are good writer or bad writer. This Study used this to judge different samples and found accuracy of writer'spersonality asshown in figure 5 .

This show how good writer and poor writer reflect on brain. Our analyzers analyze by using their vowel or chosen words technique that a person is good writer or poor writer with their functional ability of left and right brain. Good writer have logical mind and sharpen observer. Good writer make sense of words and have ability to struggle [6].

In the writer, researcher use right side of brain some use left side of brain that's why their characteristic different in their personality [7].

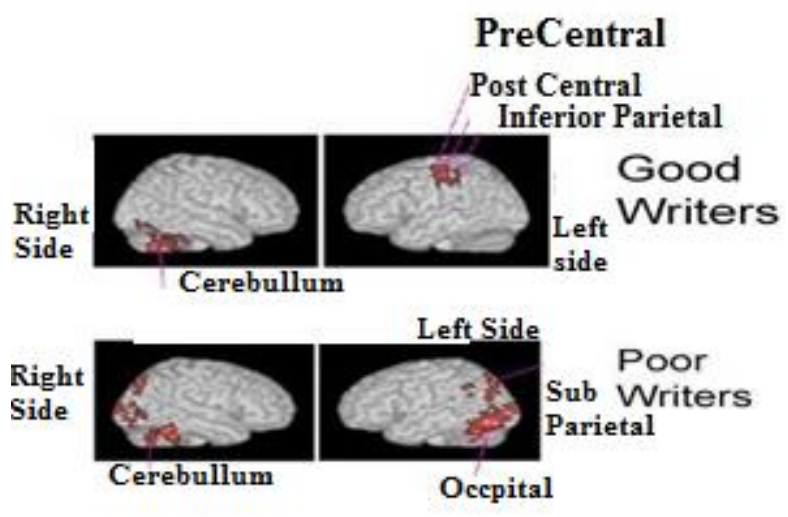

Figure 5Good and Poor Writer [6]

\subsection{Experiment and Results}

Fig 6 shows which parts of brain are were dominant during writing.

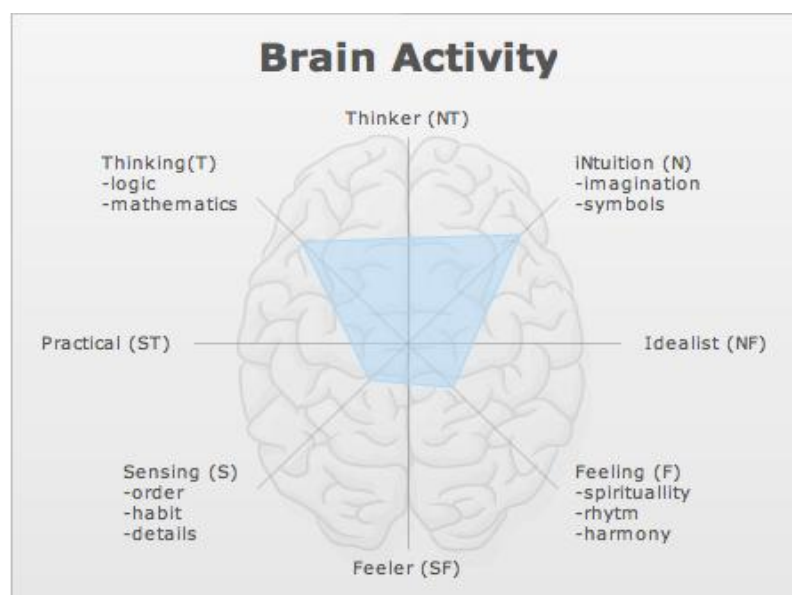

Figure 6Brain Activities[7]

Table 2Characteristic for writer Result

\begin{tabular}{|c|c|l|}
\hline Good Writer & Accuracy 98.1\% & $\begin{array}{l}\text { Sensible, logical, } \\
\text { architectural, } \\
\text { self-opinion } \\
\text { person, }\end{array}$ \\
\hline Poor Writer & $98.4 \%$ & $\begin{array}{c}\text { Lazy, fear, } \\
\text { prideful, scattered. }\end{array}$ \\
\hline Moods & Brain waves & $\begin{array}{c}\text { Stressed, Happy. } \\
\text { Lazy. }\end{array}$ \\
\hline
\end{tabular}

In figure 6 brain Activity is represent how person pick words according to their mental ability. Brain has four parts

These four functions are givenin figure 7.There activate during writing. Brain has two major functions Left Brain functions or Right Brain Functions. Left brain Functionsuse logics, detail oriented facts rules words and language present, past, math,science comprehend knowing acknowledges, short term memory learn new task, safe, serial processing and on other side Right Brain functions uses feelings, long term memory, automatic processing of new tasks, rules, symbols, present and

future,philosophy,religion, believes, appreciates,spatial 
perception knows object function, fantasy based presents possibilities, impetuous, risk taking, parallel processing. HBDL Hermann Brain Dominance Instrument measure thinking preference and BASH Analyzer define characteristic on the basis of these personality models. All five features analyze human behavior, perspective, comparison result, page margin, vowels, and preposition and also our research tell the writer moods on the basic of wave model characteristic.

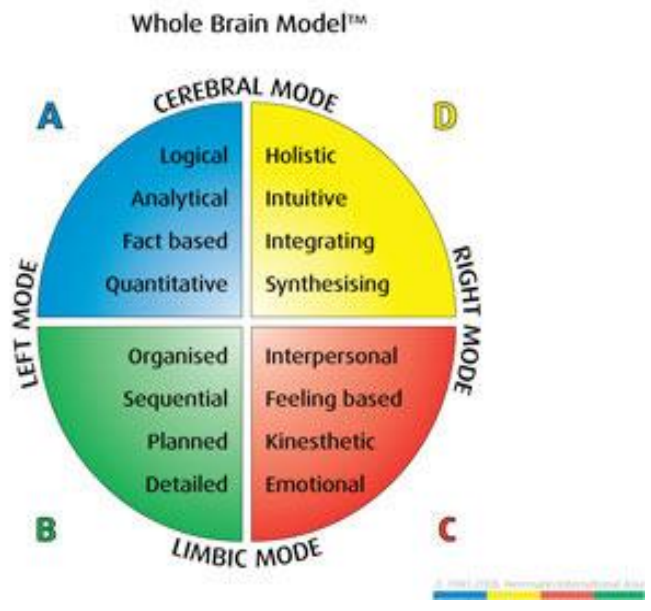

Figure 7Whole Brain Model[8]

Table2 defines result regarding filtered words and take result according to preposition analyses using Table3on the basis of good \& bad writer characteristic with help of Brain Activity and Brain Models [8][9].

\section{GOOD AND BAD WRITER}

BASH analyzer provide guidelines that how to be a good writer and how to avoid from bad writing styles [10][11]

\subsection{Good Writer Characteristics}

Good writer characteristics are as follows:-

i. Good writer always has a clearly define purpose and thoughts.

ii. Information is totally to the point.

iii. Words are appropriate, correct grammar, verb, sentence are concise.

iv. Good writer always have writing goals and fact reasoning thoughts.

v. Keen observer

vi. Correct Punctuation or spelling.

vii. Joe Chernov says, Good writer always try to tells a full story.

viii. Provide Reasoning facts.

ix. Good writer provide motivation for reader to study in depth by giving informative knowledge.

x. A good writer will always find it very hard to fill a single page.

\subsection{Bad Writer Characteristics}

Characteristics of Bad writer are as follows:

i. A bad writer will always find it easy. (Aubrey Kalitera, Why Father Why, 1983) ii. A bad writer is a writer who always says more than he thinks or observe. A good writer--and here we must be careful if we wish to arrive at any real insight--is a writer who does not say more than he thinks.

(Walter Benjamin, journal entry, Selected Writings: Volume 3, 1935-1938)

iii. The difference between a good and a bad writer is shown by the order of his words as much as by the selection of them. (Marcus Tullius Cicero, "The Oration for Plancius," 54 B.C.)

Table 3.Personality Forum

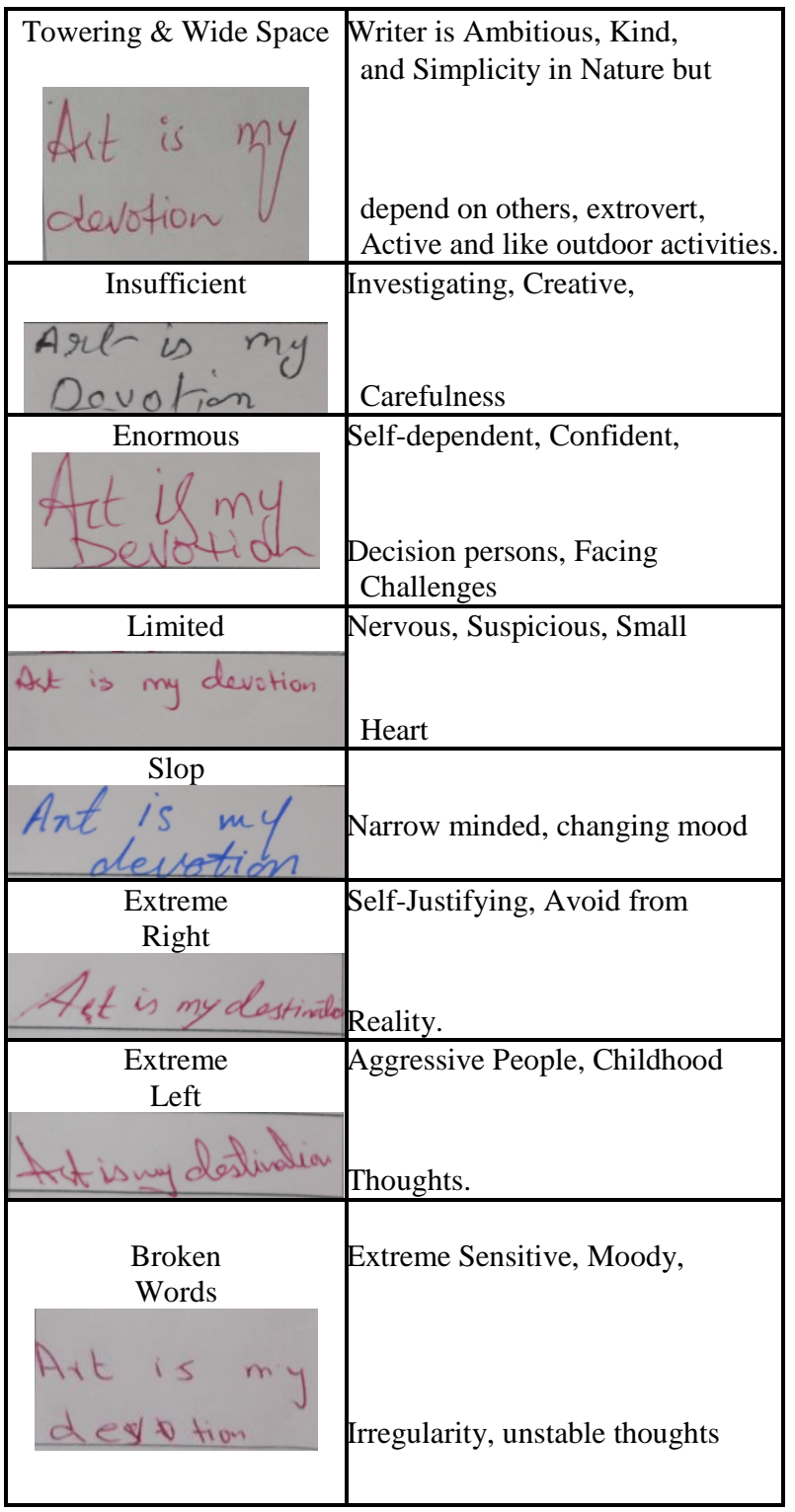

In table3Personality Forum of handwriting samples define their individual characteristic for example writing of extreme right shows good communication skills, straight, vertical writing shows independent and stability, writer that write left side means you find difficult to communicate, small or limited style of writing can show a sign of modesty, large writing indicates passionate, exitedand kind this characteristic would be calculated by the classification of SVM. 


\section{CLASSIFICATION}

In Table3 This Study extract the qualities by the classification through SVM for comparing result between words segment. Kernel based technique such as support vector machine, Bayes point machine and SVM applied for classification between words and line segment. RBF Kernel on two samples $\mathrm{x}$ and $\mathrm{x}^{\prime}$ vectors in words space.

$\mathrm{K}\left(\mathrm{x}, \mathrm{x}^{\prime}\right)=\exp \left(-\frac{\left\|x-x^{\prime}\right\| 2}{2 \sigma 2}\right)$

Equation for classification, whereas the value of $\left\|x-x^{\prime}\right\| 2$

Used distance between two vectors $\sigma$ is parameter.

\subsection{Steps of Algorithm}

Steps of algorithm are as follows.

i. Input words formulated as vectors with spacing between words.

ii. Implementation of input words to the dimensional space using RBF kernel and nonlinear kernel.

iii. Words can be compared with their start and end points distance between words.

$\mathrm{SP} \longleftrightarrow \mathrm{SE}$

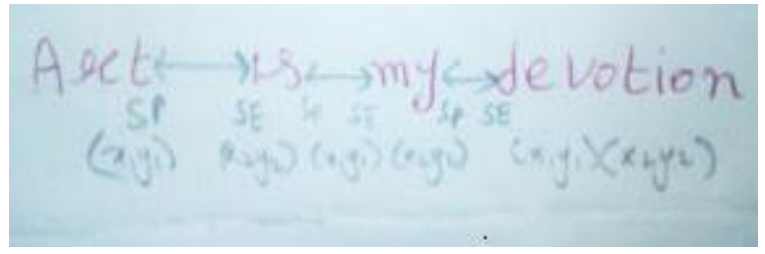

$\mathrm{SP}$ is the starting point for distance and $\mathrm{SE}$ is the End point

iv. Word spacing calculating segmentations with angle, can be calculates with $(\mathrm{x} 1, \mathrm{y} 1),(\mathrm{x} 2, \mathrm{y} 2)$

$\theta=\tan -1 \frac{y 2-y 1}{x 2-x 1}$

RBF kernel reads input features with

$\mathrm{K}\left(\mathrm{x}, \mathrm{x}^{\prime}\right)=\exp \left(-\frac{\left\|x-x^{\prime}\right\| 2}{2 \sigma 2}\right)$

v. Angle with margin extracts baseline, upper margin, and lower margin for accuracy of good and bad writer.

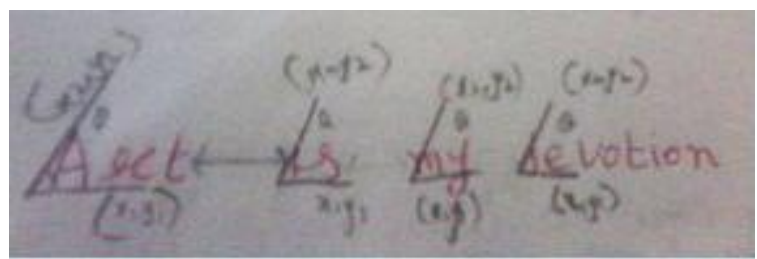

\section{CONCLUSION AND FUTURE WORK}

This study is best technique to calculate the functionality of brain functions using handwriting. Later on this study enhance with thinking behavior using brain knowledge with FMRI stages. This study also enhances about writing time that how much time this writing samplewas written using FMRI

\section{ACKNOWLEDGMENTS}

Our thanks to the experts who have contributed towards development of the template

\section{REFERENCES}

[1] Riebel,P.,(03/31/2014),Handwriting helps the brain function,

http://www.twosidesna.org/US/2014/03/31/handwritinghelps-the-brain-function/.

[2] Cvijetic,S,(2013), What are Beta Brain Waves? Improve Focus and Motivation with Beta brainwave entrainment,http://mbyl.hubpages.com/hub/What-areBeta-Brain-Waves-Focus-and-Motivation-with-Betabrainwave-entrainment

[3] Zimmer, C, (June 20, 2014), This Is Your Brain on writing,

http://www.nytimes.com/2014/06/19/science/researching -the-brain-of-writers.html?_r=0.

[4] Prasad, S.; Singh, V.K.; Sapre, A. (2010),Handwriting Analysis based on Segmentation Method for Prediction of Human Personality using Support Vector Machine,, International Joumal of Computer Applications,8(12),25-29.

[5] What are brain waves?

[6] http://www.brainworksneurotherapy.com/what-arebrainwaves.Fernette, D. and Eide, B (09/24/2014),"fMRI of Dysgraphia - Lack of Automaticity and Need for Visual Monitoring"

[7] Richards,T. L.; Brininger, V. W.; Stock, P.; Atemeier, L.; Trivedi, P. andMaravilla, K. R. (2011).Differences between good and poor child writers on fMRI contrasts for writing newly taught and highly practiced letter forms. Reading and writing, 24(5),493-516

[8] James observation, (2008), The Scientific Letter, visited on

1/12/2014,http://www.jaynejubb.com/august2013article. htm

[9] Wilson, F. R. (1999),The Hand: How Its Use Shapes the Brain, Language, and Human Culture.VintageBooks, Random House,Inc.,New York,USA.

[10] Richard NordquistExpert, (2006),"What Are the Characteristics of Good Writing?" "Writing is just work-there's no secret".Available online, hhttp://www.grammer.bout.com/od/youwritting/a/charact eristic.htm.

[11] Cameron, J. (1999) Tthe Right to write:An Invitation and Initiation Into the Writing Life,Penguin Pittman Inc.,375 Hudson Streets,New York,USA. 